\title{
Influences of changes in obesity-related parameters on progression of arteriosclerosis in hemodialysis patients: a prospective cohort study
}

Takeshi lida ${ }^{1,2}$, Satoshi Morimoto ${ }^{1 *}$, Hidenobu Okuda ${ }^{2}$, Yoshifumi Amari ${ }^{1,2}$, Takatomi Yurugi², Fumitaka Nakajima ${ }^{2}$ and Atsuhiro Ichihara ${ }^{1}$

\begin{abstract}
Background: Hemodialysis patients have a greater risk of cardiovascular disease, their major cause of death. Obesity is a risk factor for arteriosclerosis, cardiovascular disease, and mortality in the general population. Conversely, an increased body mass index (BMI) is known to be associated with better survival of hemodialysis patients. However, the influences of changes in parameters associated with obesity on arteriosclerosis in these patients have not been evaluated. Here, we evaluated the relationship between changes in parameters associated with obesity and brachial-ankle pulse wave velocity (baPWV), as an index of arteriosclerosis, in hemodialysis patients.

Methods: Two hundred and fifty-eight subjects were selected from patients undergoing stable hemodialysis. BMI, abdominal circumference (AC), visceral fat area (VFA) and subcutaneous fat areas (SFA), and baPWV were assessed at baseline and 4 years later. Ankle-brachial index and baPWV were measured on a non-dialysis day using volumeplethysmographic apparatus. Abdominal circumference was measured at the level of umbilicus by computed tomography $(\mathrm{CT})$. Body fat distribution was determined using $\mathrm{CT}$. All $\mathrm{CT}$ scans were performed on a non-dialysis day with the subject in a supine position.
\end{abstract}

Results: Sixty-one patients died during the 4-year period. Abdominal circumference, BMI, VFA, and SFA were higher, and baPWV was lower in patients who survived than in those who died. During the study period, baPWV increased and was positively correlated with the change in visceral plus subcutaneous fat area in patients whose initial VFA was $>100 \mathrm{~cm}^{2}$. There were negative correlations between the change in baPWV and changes in AC, and SFA in individuals whose VFA was $<100 \mathrm{~cm}^{2}$.

Conclusions: These data suggest that patients with a large VFA should adopt strategies aimed at reducing body weight, while patients with a small VFA should avoid undernutrition.

Keywords: Visceral fat area, Subcutaneous fat area, Brachial-ankle pulse wave velocity, Cardiovascular disease, Prognosis

\footnotetext{
* Correspondence: satoshimorimot@gmail.com

1 Department of Endocrinology and Hypertension, Tokyo Women's Medical

University, 8-1 Kawada-cho, Shinjuku-ku, Tokyo 162-8666, Japan

Full list of author information is available at the end of the article
}

(c) The Author(s). 2020 Open Access This article is licensed under a Creative Commons Attribution 4.0 International License, which permits use, sharing, adaptation, distribution and reproduction in any medium or format, as long as you give appropriate credit to the original author(s) and the source, provide a link to the Creative Commons licence, and indicate if changes were made. The images or other third party material in this article are included in the article's Creative Commons licence, unless indicated otherwise in a credit line to the material. If material is not included in the article's Creative Commons licence and your intended use is not permitted by statutory regulation or exceeds the permitted use, you will need to obtain permission directly from the copyright holder. To view a copy of this licence, visit http://creativecommons.org/licenses/by/4.0/ The Creative Commons Public Domain Dedication waiver (http://creativecommons.org/publicdomain/zero/1.0/) applies to the data made available in this article, unless otherwise stated in a credit line to the data. 


\section{Background}

Patients undergoing hemodialysis (HD) have a greater risk of arteriosclerotic complications and a poor prognosis due to the greater prevalence of cardiovascular $(\mathrm{CV})$ diseases. The risk factors include hypertension, diabetes mellitus, vascular calcification, and inflammation. Obesity has been recognized as a risk factor for arteriosclerosis and higher mortality and morbidity from $\mathrm{CV}$ disease in the general population. In addition, a positive relationship between visceral fat accumulation and arteriosclerosis has been reported in diabetic HD patients [1]. In contrast, an inverse association has been reported in female HD patients [2]. It has been proposed that the relationships between obesity-associated parameters and arteriosclerosis are complicated by the existence of malnutrition-inflammation-atherosclerosis (MIA) syndrome in these patients [3], and the influences of changes in obesity-related parameters on arteriosclerosis in patients undergoing long-term $\mathrm{HD}$ have not been evaluated.

Brachial-ankle pulse wave velocity (baPWV), which is an easily performed, non-invasive measurement, is a marker of arteriosclerosis of both central elastic and peripheral muscular components of the circulation [4]. In the general population, high baPWV is an independent predictor of mortality [5], and we have shown that baPWV is a predictor of CV outcome in patients undergoing HD [6], indicating that baPWV is a useful index of arteriosclerosis in HD patients.

Therefore, in this study, we aimed to determine the relationship between changes in parameters associated with obesity and baPWV in HD patients.

\section{Methods}

\section{Patient recruitment}

This study was approved by the ethics committee of Moriguchi Keijinkai Hospital (approval no.: 3003). All participants were enrolled after providing written informed consent. The participants were outpatients undergoing maintenance dialysis at Kadoma Keijinkai Clinic in Kadoma City, Neyagawa Keijinkai Clinic in Neyagawa City, or Moriguchi Keijinkai Clinic in Moriguchi City, Osaka, Japan. Patients were selected from those who were undergoing regular dialysis treatment and were hemodynamically stable during dialysis. Patients with malignancy and amputation of both legs were excluded in this study. The enrollment period was from January 2013 to December 2013.

\section{Patient characteristics}

At enrollment, information was collected regarding the age, gender, BMI, duration of HD, presence of diabetes, and use of anti-hyperlipidemic drugs. Diabetes was diagnosed when the patients were already under treatment with an oral hypoglycemic agent or insulin, or met the World Health Organization criteria [7] in the past or present. Pre-dialysis systolic and diastolic blood pressures (BPs) and pre-dialysis values of hemoglobin, highdensity lipoprotein cholesterol (HDL-c), low-density lipoprotein cholesterol (LDL-c), triglyceride, uric acid, creatinine, c-reactive protein (CRP), calcium, inorganic phosphorus, intact parathyroid hormone, albumin, and hemoglobin A1c were measured on the first dialysis day of the week. Post-dialysis value of human atrial natriuretic peptide (hANP), brain natriuretic peptide (BNP), and cardiothoracic ratio (CTR) were measured on the first dialysis day of the week.

\section{Ankle-brachial index and brachial-ankle pulse wave velocity}

Ankle-brachial index (ABI) and baPWV were measured on a non-dialysis day using a volume-plethysmographic apparatus (Omron Healthcare Co., Ltd., Kyoto, Japan), as previously described [8]. The higher of the values for each leg was accepted as the baPWV value. Because baPWV cannot be estimated accurately when ABI is < 0.9 , due to a reduction induced by arterial occlusion [9], lower limbs with an ABI of $<0.9$ were excluded from the analysis of baPWV.

\section{Computed tomography}

Abdominal circumference (AC) was measured at the level of the umbilicus by computed tomography (CT) using Ziostation 2 software (Ziosoft, Tokyo, Japan). Body fat distribution was determined using CT. All CT scans were performed on a non-dialysis day with the subject in a supine position, using an 80-slice multidetector CT scanner (Aquilion PRIME, Canon medical systems Corporation, Tochigi, Japan). Three-millimeter-thick slices were acquired. The subcutaneous fat layer was defined as the layer lying between the skin and abdominal muscle that showed attenuation from -60 to $-160 \mathrm{HU}$. The component of the image with the same density as the subcutaneous fat layer in the abdominal cavity was defined as the visceral fat. The subcutaneous fat area (SFA) and VFA were measured in a slice at the level of the umbilicus.

The CT attenuation of adipose tissue is thought to be approximately -60 to $-160 \mathrm{HU}$. However, when adipose tissue is edematous, this value is higher because of the presence of water (attenuation $=0$ ). In such cases, accurate measurement of fat area by CT is impossible. Therefore, we did not include patients with gross edema in our analysis. In our study, the presence of gross edema was defined by the area with a radiodensity of 60 to $-160 \mathrm{HU}$ being smaller than that with a radiodensity of -30 to $-50 \mathrm{HU}$ at the level of the umbilicus. 
Consequently, 12 patients were not included in our analysis.

\section{Study protocol}

Patient characteristics were recorded at baseline, and the BMI, AC, VFA, SFA, and baPWV were measured at baseline and 4 years later. Comparison of patients' characteristics between those who survived and those who died was done. Of the patients who survived, those with complete data at baseline and 4 years later were analyzed for the influences of changes in obesity-related factors on arteriosclerosis over a 4-year period.

\section{Statistical analysis}

Data are expressed as mean \pm SD. Statistical comparisons between patients who survived and those who died were performed using Student's $t$ test or Fisher's exact test. Paired $t$ tests were used to assess changes over the 4-year period in patients who survived and had complete data at baseline and 4 years later. Pearson's correlation coefficient was used to evaluate the relationships between the change in baPWV and changes in other obesity-related parameters over the period of the study. $P<0.05$ was considered to represent statistical significance. All analyses were performed using EZR (Saitama Medical Center, Jichi Medical University, Saitama, Japan) [10].

\section{Results}

A total of 258 patients were enrolled in the study. Table 1 shows details of the characteristics of the study subjects. Out of 258 patients, 61 patients died within 4 years. The patients' flowchart is presented in Fig. 1.

Comparison of patients' characteristics between those who survived and those who died is shown in Table 2. Age, presence of diabetes, hANP, BNP, CTR, and baPWV were significantly higher in patients who died than in those who survived. BMI, serum creatinine, serum albumin, AC, VFA, and SFA were significantly lower in patients who died than in those who survived.

Of the patients who survived, 102 patients with complete data were analyzed for the influences of changes in obesity-related factors on arteriosclerosis over a 4-year period. The characteristics of these $102 \mathrm{pa}$ tients at baseline are shown in Table 3. The BMI (initial value $22.4 \pm 3.0 \mathrm{~kg} / \mathrm{m}^{2}$, final value $22.2 \pm 3.3 \mathrm{~kg} / \mathrm{m}^{2}$ ), AC (initial value $83.4 \pm 8.6 \mathrm{~cm}$, final value $82.6 \pm 9.4 \mathrm{~cm}$ ), VFA (initial value $86.2 \pm 54.4 \mathrm{~cm}^{2}$, final value $85.7 \pm$ $54.0 \mathrm{~cm}^{2}$ ), and SFA (initial value $120.1 \pm 62.7 \mathrm{~cm}^{2}$, final value $117.9 \pm 60.2 \mathrm{~cm}^{2}$ ) did not significantly change during the study period. baPWV significantly increased (initial value $1913 \pm 446 \mathrm{~cm} / \mathrm{s}$, final value $2029 \pm 546 \mathrm{~cm} / \mathrm{s}$; $P<0.01$ ), while BPs did not significantly change (sBP initial value $145 \pm 22 \mathrm{mmHg}$, final value $145 \pm 21$
Table 1 Characteristics of the study subjects

\begin{tabular}{|c|c|}
\hline Number of patients & 258 \\
\hline Age (years) & $67.4 \pm 12.1$ \\
\hline Gender (m/f) & $146 / 112$ \\
\hline Body mass index $\left(\mathrm{kg} / \mathrm{m}^{2}\right)$ & $22.2 \pm 3.7$ \\
\hline Dialysis history (months) & $63.2 \pm 55.4$ \\
\hline Diabetes (\%) & $123(47.7)$ \\
\hline Hyperlipidemia drugs (\%) & 35 (13.6) \\
\hline Systolic BP (mmHg) & $152 \pm 22$ \\
\hline Diastolic BP (mmHg) & $76 \pm 14$ \\
\hline \multicolumn{2}{|l|}{ Laboratory study } \\
\hline Hemoglobin (g/dl) & $10.8 \pm 1.0$ \\
\hline High-density lipoprotein cholesterol (mg/dl) & $46.8 \pm 14.6$ \\
\hline Low-density lipoprotein cholesterol (mg/dl) & $88.7 \pm 29.4$ \\
\hline Triglyceride (mg/dl) & $103.2 \pm 65.5$ \\
\hline Uric acid (mg/dl) & $7.2 \pm 1.3$ \\
\hline Creatinine (mg/dl) & $9.6 \pm 2.5$ \\
\hline C-reactive protein (mg/dl) & $0.34 \pm 0.70$ \\
\hline $\mathrm{Ca}(\mathrm{mg} / \mathrm{dl})$ & $8.9 \pm 0.5$ \\
\hline Inorganic phosphorus (mg/dl) & $5.2 \pm 1.2$ \\
\hline Intact-parathyroid hormone (pg/ml) & $143.4 \pm 85.0$ \\
\hline Albumin $(\mathrm{g} / \mathrm{dl})$ & $3.7 \pm 0.3$ \\
\hline Hemoglobin A1c (\%) & $5.34 \pm 0.85$ \\
\hline Human atrial natriuretic polypeptide $(\mathrm{pg} / \mathrm{ml})$ & $69.3 \pm 107.9$ \\
\hline Brain natriuretic peptide $(\mathrm{pg} / \mathrm{ml})$ & $264.5 \pm 404.1$ \\
\hline Cardiothoracic ratio (\%) & $52.3 \pm 5.3$ \\
\hline Brachial-ankle pulse wave velocity $(\mathrm{cm} / \mathrm{s})$ & $2041 \pm 654$ \\
\hline Abdominal circumference $(\mathrm{cm})$ & $83.5 \pm 10.3$ \\
\hline Visceral fat area $\left(\mathrm{cm}^{2}\right)$ & $84.7 \pm 59.2$ \\
\hline Subcutaneous fat area $\left(\mathrm{cm}^{2}\right)$ & $118.2 \pm 73.0$ \\
\hline
\end{tabular}

Values are expressed as mean \pm SD

mmHg; dBP initial value $79 \pm 12 \mathrm{mmHg}$, final value 77 $\pm 13 \mathrm{mmHg}$ ).

Of these 102 patients, 36 had an initial VFA of $\geq 100$ $\mathrm{cm}^{2}$, which meets the Japanese obesity criteria [11]. In these patients, the change in baPWV over 4 years was significantly positively correlated with the changes of VFA + SFA $(r=0.33, P<0.05)$ (Table 4$)$. Sixty-six patients had an initial VFA of $<100 \mathrm{~cm}^{2}$. In these patients, the change in baPWV over 4 years was significantly negatively correlated with the changes in AC $(r=-0.333, P<0.01)$, SFA $(r=-0.367, P<0.01)$, and VFA + SFA $(r=-0.297, P<0.05)($ Table 4$)$.

\section{Discussion}

There were three main findings in this study. First, baPWV was higher and BMI, AC, VFA, and SFA were lower in the patients who died than in those who 


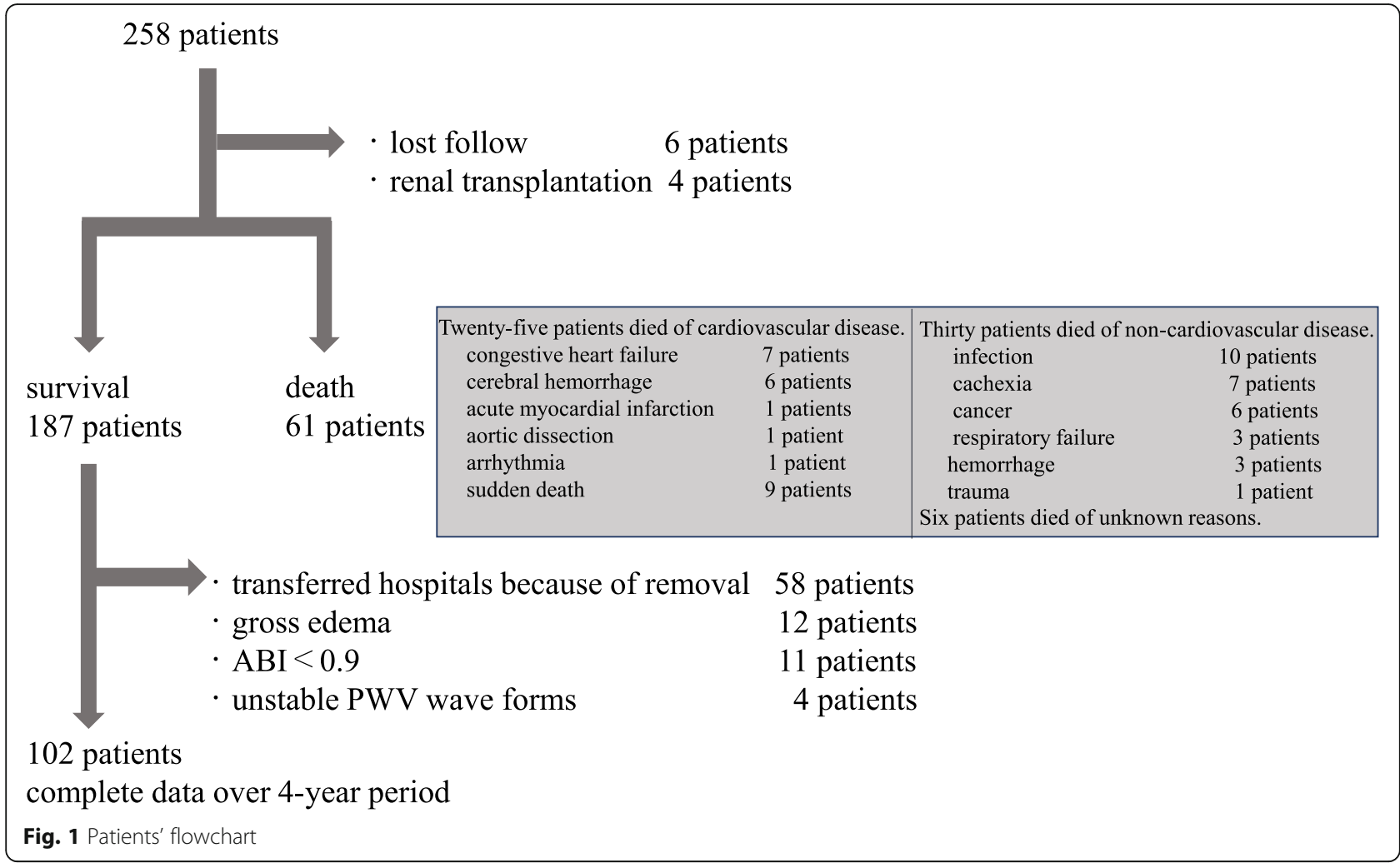

survived. Second, baPWV increased over the 4-year period of the study. Third, the change in baPWV was positively correlated with the changes in obesity-related parameters in patients whose initial VFA was $\geq 100 \mathrm{~cm}^{2}$ and was negatively correlated with the change in obesity-related parameters in those whose initial VFA was $<100 \mathrm{~cm}^{2}$. These findings suggest that increasing obesity in individuals with a large visceral fat area and decreasing adiposity in individuals with a low visceral fat area are both associated with the progression of arteriosclerosis.

\section{Characteristics of patients who survived and those who died}

There were significant differences in some of the characteristics of the patients who died and those who survived the 4-year study period. BMI, serum albumin, and adiposity were significantly lower among those who died. Thus, in this study, good nutritional status and slightly greater fat accumulation were beneficial for HD patients, trends which are consistent with previous reports [12, 13]. Higher $\mathrm{AC}$ was also beneficial in our study. The hANP and BNP are known to be independent risk factors for $\mathrm{CV}$ and overall mortality in $\mathrm{HD}$ patients [14, 15], and in our study, they were significantly higher in the patients who died. High baPWV is thought to be a risk factor for $\mathrm{CV}$ and overall mortality [5], and in terms of the mortality of HD patients, the same trends of high
CTR [16] and concomitant diabetes [13] were identified in this study as in previous reports. In addition, the mortality rate during 4 years was $24.6 \%$ in this study, which is almost equivalent to that of Japanese dialysis patients whose crude death rate is about $10 \%$ /year [17]. On the basis of these consistent findings, the patients in our study appear to be representative HD patients.

\section{Time-dependent change in brachial-ankle pulse wave velocity in hemodialysis patients}

Patients undergoing HD have a greater risk of arteriosclerotic complications and a poor prognosis due to the greater prevalence of CV diseases [18-20]. Most HD patients are thought to have developed arteriosclerosis by the time they commence HD, and afterwards, arteriosclerosis is thought to be accelerated [21]. However, the natural course of PWV has not been comprehensively assessed in longitudinal studies. Avramovski et al. showed in a comparison of 80 HD patients and 60 controls that carotid-femoral PWV was higher in HD patients at baseline, but increased more in these patients over a 36-month period [22]. In the present study, we have shown that baPWV increased during a 4-year period in $102 \mathrm{HD}$ patients. PWV has been reported to reflect not only arterial stiffness but also the BPs at the time of PW measurement [23]. In this study, however, the BPs did not show significant changes. Therefore, high baPWV is considered to reflect progression of 
Table 2 Comparison of characteristics of the patients who survived and those who died

\begin{tabular}{|c|c|c|c|}
\hline & Survival & Death & \\
\hline Number of patients & 187 & 61 & \\
\hline Age (years) & $65.7 \pm 12.1$ & $73.7 \pm 9.8$ & $P<0.01$ \\
\hline Gender (m/f) & $102 / 85$ & $35 / 26$ & NS \\
\hline Body mass index $\left(\mathrm{kg} / \mathrm{m}^{2}\right)$ & $22.5 \pm 3.6$ & $20.9 \pm 3.5$ & $P<0.01$ \\
\hline Dialysis history (months) & $64.9 \pm 55.7$ & $61.0 \pm 57.2$ & NS \\
\hline Diabetes (\%) & $80(43)$ & $41(67)$ & $P<0.01$ \\
\hline Hyperlipidemia drugs (\%) & $22(12)$ & $12(20)$ & NS \\
\hline Systolic BP (mmHg) & $152 \pm 20$ & $150 \pm 26$ & NS \\
\hline Diastolic BP (mmHg) & $77 \pm 14$ & $73 \pm 14$ & NS \\
\hline \multicolumn{4}{|l|}{ Laboratory study } \\
\hline Hemoglobin $(\mathrm{g} / \mathrm{dl})$ & $10.8 \pm 0.9$ & $10.9 \pm 1.0$ & NS \\
\hline High-density lipoprotein cholesterol (mg/dl) & $47.9 \pm 15.3$ & $43.9 \pm 12.7$ & NS \\
\hline Low-density lipoprotein cholesterol (mg/dl) & $87.5 \pm 29.2$ & $91.6 \pm 30.2$ & NS \\
\hline Triglyceride (mg/dl) & $100 \pm 58$ & $114 \pm 87$ & NS \\
\hline Uric acid (mg/dl) & $7.2 \pm 1.4$ & $7.0 \pm 1.3$ & NS \\
\hline Creatinine $(\mathrm{mg} / \mathrm{dl})$ & $9.9 \pm 2.6$ & $8.6 \pm 2.1$ & $P<0.01$ \\
\hline C-reactive protein (mg/dl) & $0.3 \pm 0.7$ & $0.5 \pm 0.8$ & NS \\
\hline $\mathrm{Ca}(\mathrm{mg} / \mathrm{dl})$ & $8.9 \pm 0.5$ & $8.9 \pm 0.5$ & NS \\
\hline Inorganic phosphorus (mg/dl) & $5.2 \pm 1.1$ & $5.1 \pm 1.0$ & NS \\
\hline Intact-parathyroid hormone (pg/ml) & $139 \pm 80$ & $151 \pm 96$ & NS \\
\hline Albumin $(\mathrm{g} / \mathrm{dl})$ & $3.7 \pm 0.3$ & $3.5 \pm 0.4$ & $P<0.01$ \\
\hline Hemoglobin A1c (\%) & $5.3 \pm 0.8$ & $5.5 \pm 1.0$ & NS \\
\hline Human atrial natriuretic polypeptide (pg/ml) & $60 \pm 55$ & $103 \pm 197$ & $P<0.01$ \\
\hline Brain natriuretic peptide $(\mathrm{pg} / \mathrm{ml})$ & $216 \pm 241$ & $429 \pm 693$ & $P<0.01$ \\
\hline Cardiothoracic ratio (\%) & $51.7 \pm 4.7$ & $54.8 \pm 6.3$ & $P<0.01$ \\
\hline Brachial-ankle pulse wave velocity $(\mathrm{cm} / \mathrm{s})$ & $1971 \pm 540$ & $2317 \pm 894$ & $P<0.01$ \\
\hline Abdominal circumference $(\mathrm{cm})$ & $84.4 \pm 10.3$ & $80.6 \pm 10.1$ & $P<0.05$ \\
\hline Visceral fat area $\left(\mathrm{cm}^{2}\right)$ & $89.8 \pm 62.1$ & $69.2 \pm 49.7$ & $P<0.05$ \\
\hline Subcutaneous fat area $\left(\mathrm{cm}^{2}\right)$ & $124.8 \pm 71.3$ & $97.6 \pm 76.3$ & $P<0.05$ \\
\hline
\end{tabular}

Values are expressed as mean \pm SD

arteriosclerosis, supporting the notion that the natural course of arteriosclerosis is accelerated in patients undergoing HD.

\section{Influences of changes in obesity-related parameters on arteriosclerosis in hemodialysis patients}

Accumulation of visceral fat is a risk factor for arteriosclerosis. Abdominal visceral fat mass is positively associated with carotid-femoral PWV in healthy subjects [24]. There is also a positive relationship between abdominal VFA and baPWV in diabetic patients [25] and diabetic HD patients [1]. However, an inverse association was found between abdominal visceral fatness and baPWV in female HD patients [2]. Thus, it is unclear whether the accumulation of visceral fat is a risk factor for arteriosclerosis in HD patients. In addition, overweight, hypertension, and hyperlipidemia, which are cardiovascular risk factors in the general population, have been reported to correlate with lower mortality in HD patients, a phenomenon that is known as "reverse epidemiology," the "risk factor paradox," and the "obesity paradox."

In this study, increasing obesity in patients with high VFA and decreasing adiposity in patients with low VFA were associated with the development of arteriosclerosis. There are likely to be two different etiologies that may explain this phenomenon. One is the metabolic syndrome, and the other is the MIA syndrome. Obesity and insulin resistance are believed to be at the core of most cases of metabolic syndrome, and patients may have a greater risk of diseases such as cardiovascular disease [26]. The MIA syndrome features a strong relationship 
Table 3 Characteristics of the surviving patients who were included in the final analysis

\begin{tabular}{|c|c|c|}
\hline & Baseline & Study end \\
\hline Number of patients & 102 & \\
\hline Age (years) & $65.4 \pm 12.1$ & - \\
\hline Gender (m/f) & $54 / 48$ & - \\
\hline Body mass index $\left(\mathrm{kg} / \mathrm{m}^{2}\right)$ & $22.4 \pm 3.0$ & $22.2 \pm 3.3$ \\
\hline Dialysis history (months) & $66.4 \pm 57.6$ & - \\
\hline Diabetes (\%) & $42(41)$ & - \\
\hline Hyperlipidemia drugs (\%) & $10(9.8)$ & - \\
\hline Systolic BP (mmHg) & $145 \pm 22$ & $145 \pm 21$ \\
\hline Diastolic BP (mmHg) & $79 \pm 12$ & $77 \pm 13$ \\
\hline \multicolumn{3}{|l|}{ Laboratory study } \\
\hline Hemoglobin (g/dl) & $10.9 \pm 0.9$ & - \\
\hline High-density lipoprotein cholesterol (mg/dl) & $47.9 \pm 16.0$ & - \\
\hline Low-density lipoprotein cholesterol (mg/dl) & $86.1 \pm 28.4$ & - \\
\hline Triglyceride (mg/dl) & $96.9 \pm 54.0$ & - \\
\hline Uric acid (mg/dl) & $7.3 \pm 1.2$ & - \\
\hline Creatinine $(\mathrm{mg} / \mathrm{dl})$ & $10.2 \pm 2.6$ & - \\
\hline C-reactive protein (mg/dl) & $0.25 \pm 0.70$ & - \\
\hline $\mathrm{Ca}(\mathrm{mg} / \mathrm{dl})$ & $8.9 \pm 0.6$ & - \\
\hline Inorganic phosphorus (mg/dl) & $5.1 \pm 1.1$ & - \\
\hline Intact parathyroid hormone (pg/ml) & $129.6 \pm 82.8$ & - \\
\hline Albumin $(\mathrm{g} / \mathrm{dl})$ & $3.7 \pm 0.3$ & - \\
\hline Hemoglobin A1c (\%) & $5.23 \pm 0.75$ & - \\
\hline Human atrial natriuretic polypeptide (pg/ml) & $62.7 \pm 63.5$ & - \\
\hline Brain natriuretic peptide $(\mathrm{pg} / \mathrm{ml})$ & $214.3 \pm 263.5$ & - \\
\hline Cardiothoracic ratio (\%) & $51.7 \pm 4.8$ & - \\
\hline Brachial-ankle pulse wave velocity $(\mathrm{cm} / \mathrm{s})$ & $1913 \pm 446$ & $2029 \pm 546$ \\
\hline Abdominal circumference $(\mathrm{cm})$ & $83.4 \pm 8.6$ & $82.6 \pm 9.4$ \\
\hline Visceral fat area $\left(\mathrm{cm}^{2}\right)$ & $86.2 \pm 54.4$ & $85.7 \pm 54.0$ \\
\hline Subcutaneous fat area $\left(\mathrm{cm}^{2}\right)$ & $120.1 \pm 62.7$ & $117.9 \pm 60.2$ \\
\hline
\end{tabular}

Values are expressed as mean \pm SD

between malnutrition, inflammation, and atherosclerosis in dialysis patients, associated with a high mortality rate [3]. In this study, increasing obesity in patients with high VFA was associated with the development of arteriosclerosis, likely due to metabolic syndrome, whereas decreasing adiposity in patients with low VFA was also associated with the development of arteriosclerosis, but this was likely due to the MIA syndrome. Thus, the present study suggests that patients with a large visceral fat area are advised to adopt strategies aimed at reducing body weight, while patients with a small visceral fat area should avoid undernutrition. Patients failing to follow

Table 4 Correlation with $\triangle \mathrm{baPW}$

\begin{tabular}{llllll}
\hline & $\boldsymbol{\Delta B M I}$ & $\boldsymbol{\Delta A C}$ & $\boldsymbol{\Delta V F A}$ & $\boldsymbol{\Delta S F A}$ & $\boldsymbol{\Delta V F A}+$ SFA \\
\hline All patients $(n=102)$ & $r=-0.0532$ & $r=-0.156$ & $r=0.0458$ & $r=-0.0939$ & $r=-0.0229$ \\
& $p=0.595$ & $p=0.118$ & $p=0.648$ & $p=0.348$ & $p=0.819$ \\
Patients with VFA $\geq 100 \mathrm{~cm}^{2}(n=36)$ & $r=0.131$ & $r=0.0299$ & $r=0.281$ & $r=0.289$ & $r=0.33$ \\
& $p=0.448$ & $p=0.862$ & $p=0.0965$ & $p=0.0875$ & $p=0.0491$ \\
Patients with VFA $<100 \mathrm{~cm}^{2}(n=66)$ & $r=-0.237$ & $r=-0.333$ & $r=-0.177$ & $r=-0.367$ & $r=-0.297$ \\
& $p=0.0549$ & $p=0.00626$ & $p=0.155$ & $p=0.00245$ & $p=0.0156$ \\
\hline
\end{tabular}

baPWV brachial-ankle pulse wave velocity, $B M I$ body mass index, $A C$ abdominal circumference, VFA visceral fat area, SFA subcutaneous fat area 
these instructions may have a high risk of arteriosclerosis and should be followed carefully.

\section{Limitations}

Several limitations of the present study should be mentioned. First, a small number of patients were studied. Second, because many patients were lost to follow-up because they died or because of missing data, no more than $40 \%$ of enrolled patients were analyzed for the influences of changes in obesity-related factors on arteriosclerosis. Third, we did not compare changes in baPWV with general population. Fourth, we do not have data investigating if reducing VFA and SFA can improve the prognosis of patients with large VFA. Moreover, associations between obesity-related parameters, such as adipocytokines and arteriosclerosis, were not evaluated in this study. Larger-scale longitudinal studies investigating the mechanism by which a change in VFA affects the progression of arteriosclerosis in HD patients are required.

\section{Conclusions}

In this study, we found that over the 4-year period, baPWV increased, and the change in baPWV was higher in patients who initially had a high VFA and gained additional adipose tissue mass, and was also higher in patients who initially had a low VFA and lost adipose tissue mass. Physicians should advise patients with a large visceral fat area not to gain weight, and conversely, those with small visceral fat area not to risk undernutrition.

\section{Abbreviations \\ ABI: Ankle-brachial index; AC: Abdominal circumference; baPWV: Brachial- ankle pulse wave velocity; BMl: Body mass index; BNP: Brain natriuretic peptide; BPs: Blood pressures; CRP: C-reactive protein; $\mathrm{CT}$ : Computed tomography; CTR: Cardiothoracic ratio; CV: Cardiovascular; HD: Hemodialysis; hANP: Human atrial natriuretic peptide; HDL-c: High-density lipoprotein cholesterol; LDL-c: Low-density lipoprotein cholesterol; MIA: Malnutrition- inflammation-atherosclerosis; SFA: Subcutaneous fat areas; VFA: Visceral fat area}

\section{Acknowledgements}

We thank Mark Cleasby, PhD, from Edanz Group (www.edanzediting.com/ac) for editing a draft of this manuscript.

\section{Authors' contributions}

All author contributed to this manuscript. Conception and design, analysis and interpretation of data: TI, SM, and Al. Drafting and revising the manuscript: TI and SM. Providing intellectual content of critical importance to the work described: $\mathrm{TI}$ and SM. Collection and assembly of data: $\mathrm{Tl}, \mathrm{HO}$, YA, TY, and FN. Final approval of the version to be published: Al. All authors read and approved the final manuscript.

\section{Funding}

This work was supported in part by grants from the Ministry of Education, Culture, Sports, Science and Technology of Japan (19K08497 to SM).

\section{Availability of data and materials}

The datasets used and analyzed during the current study are available from the corresponding author on reasonable request.

\section{Ethics approval and consent to participate}

This prospective study was conducted in accordance with the Declaration of Helsinki and good clinical practice guidelines and was approved by the ethics committee of Moriguchi Keijinkai Hospital (approval no.: 3003). All participants were enrolled after providing written informed consent.

\section{Consent for publication}

All participants agreed for publication.

\section{Competing interests}

The authors declare that they have no competing interests.

\section{Author details}

${ }^{1}$ Department of Endocrinology and Hypertension, Tokyo Women's Medical University, 8-1 Kawada-cho, Shinjuku-ku, Tokyo 162-8666, Japan. ${ }^{2}$ Department of Nephrology and Dialysis, Moriguchi Keijinkai Hospital, 2-47-12

Yagumohigashimati, Moriguchi, Osaka, Japan.

Received: 7 May 2020 Accepted: 13 November 2020

Published online: 25 November 2020

\section{References}

1. Yurugi T, Morimoto S, Okamoto T, Amari Y, Kasuno Y, Fukui M, et al. Accumulation of visceral fat in maintenance hemodialysis patients. Clin Exp Nephrol. 2012;16(1):156-63.

2. Kato A, Takita T, Kumagai $\mathrm{H}$. Relationship between arterial stiffening and skeletal muscle atrophy in hemodialysis patients: a gender comparative study. J Cachexia Sarcopenia Muscle. 2014;5(3):247-9.

3. Jeznach-Steinhagen A, Slotwinski R, Szczygiel B. Malnutrition, inflammation, atherosclerosis in hemodialysis patients. Rocz Panstw Zakl Hig. 2007:58(1):83-8.

4. Ghiadoni L, Taddei S, Virdis A, Sudano I, Di Legge V, Meola M, et al. Endothelial function and common carotid artery wall thickening in patients with essential hypertension. Hypertension. 1998;32(1):25-32.

5. Turin TC, Kita Y, Rumana N, Takashima N, Kadota A, Matsui K, et al. Brachialankle pulse wave velocity predicts all-cause mortality in the general population: findings from the Takashima study. Japan Hypertens Res. 2010; 33(9):922-5

6. Morimoto S, Yurugi T, Aota Y, Sakuma T, Jo F, Nishikawa M, et al. Prognostic significance of ankle-brachial index, brachial-ankle pulse wave velocity, flowmediated dilation, and nitroglycerin-mediated dilation in end-stage renal disease. Am J Nephrol. 2009;30(1):55-63.

7. American DA. Diagnosis and classification of diabetes mellitus. Diabetes Care. 2006;29(Suppl 1):S43-8.

8. Yamashina A, Tomiyama H, Takeda K, Tsuda H, Arai T, Hirose K, et al. Validity, reproducibility, and clinical significance of noninvasive brachial-ankle pulse wave velocity measurement. Hypertens Res. 2002;25(3):359-64.

9. Yokoyama H, Shoji T, Kimoto E, Shinohara K, Tanaka S, Koyama H, et al. Pulse wave velocity in lower-limb arteries among diabetic patients with peripheral arterial disease. J Atheroscler Thromb. 2003;10(4):253-8.

10. Kanda Y. Investigation of the freely available easy-to-use software 'EZR' for medical statistics. Bone Marrow Transplant. 2012:48:452.

11. Examination Committee of Criteria for 'Obesity Disease' in J, Japan Society for the Study of O. New criteria for 'obesity disease' in Japan. Circ J. 2002; 66(11):987-92

12. Kalantar-Zadeh K, Block G, Humphreys MH, Kopple JD. Reverse epidemiology of cardiovascular risk factors in maintenance dialysis patients. Kidney Int. 2003;63(3):793-808.

13. Lowrie EG, Lew NL. Death risk in hemodialysis patients: the predictive value of commonly measured variables and an evaluation of death rate differences between facilities. Am J Kidney Dis. 1990;15(5):458-82

14. Cataliotti A, Malatino LS, Jougasaki M, Zoccali C, Castellino P, Giacone G, et al. Circulating natriuretic peptide concentrations in patients with endstage renal disease: role of brain natriuretic peptide as a biomarker for ventricular remodeling. Mayo Clin Proc. 2001;76(11):1111-9.

15. Zoccali C, Mallamaci F, Benedetto FA, Tripepi G, Parlongo S, Cataliotti A et al. Cardiac natriuretic peptides are related to left ventricular mass and function and predict mortality in dialysis patients. J Am Soc Nephrol. 2001; 12(7):1508-15.

16. Ogata H, Kumasawa J, Fukuma S, Mizobuchi M, Kinugasa E, Fukagawa M, et al. The cardiothoracic ratio and all-cause and cardiovascular disease 
mortality in patients undergoing maintenance hemodialysis: results of the MBD-5D study. Clin Exp Nephrol. 2017;21(5):797-806.

17. Nitta K, Masakane I, Hanafusa N, Taniguhi M, Hasegawa T, et al. Annual dialysis data report 2017, JSDT Renal Data Registry. Japanese Soc Dial Ther. 2018;51:699-766

18. Levey AS, Beto JA, Coronado BE, Eknoyan G, Foley RN, Kasiske BL, et al. Controlling the epidemic of cardiovascular disease in chronic renal disease: what do we know? What do we need to learn? Where do we go from here? National Kidney Foundation Task Force on Cardiovascular Disease. Am J Kidney Dis. 1998;32(5):853-906.

19. Tong J, Liu M, Li H, Luo Z, Zhong X, Huang J, et al. Mortality and associated risk factors in dialysis patients with cardiovascular disease. Kidney Blood Press Res. 2016:41(4):479-87.

20. Mark PB. Strategies to manage cardiovascular risk in chronic kidney disease. Nephrol Dial Transplant. 2018;33(1):23-5.

21. Fischer EC, Zocalo Y, Galli C, Wray S, Bia D. Arterial stiffness and renal replacement therapy: a controversial topic. Int J Nephrol. 2015. https://doi. org/10.1155/2015/729609.

22. Avramovski P, Janakievska P, Sotiroski K, Sikole A. Accelerated progression of arterial stiffness in dialysis patients compared with the general population. Korean J Intern Med. 2013;28(4):464-74.

23. Tomiyama H, Matsumoto C, Shiina K, Yamashina A. Brachial-ankle PWV: current status and future directions as a useful marker in the management of cardiovascular disease and/or cardiovascular risk factors. J Atheroscler Thromb. 2016;23(2):128-46.

24. Lee Y, Shin H, Vassy JL, Kim JT, Cho SI, Kang SM, et al. Comparison of regional body composition and its relation with cardiometabolic risk between BMI-matched young and old subjects. Atherosclerosis. 2012;224(1): 258-65.

25. Anan F, Masaki T, Umeno Y, Iwao T, Yonemochi H, Eshima N, et al. Correlations of visceral fat accumulation and atherosclerosis in Japanese patients with type 2 diabetes mellitus. Metabolism. 2008;57(2):280-4.

26. Samson SL, Garber AJ. Metabolic syndrome. Endocrinol Metab Clin N Am. 2014;43(1):1-23.

\section{Publisher's Note}

Springer Nature remains neutral with regard to jurisdictional claims in published maps and institutional affiliations.

Ready to submit your research? Choose BMC and benefit from:

- fast, convenient online submission

- thorough peer review by experienced researchers in your field

- rapid publication on acceptance

- support for research data, including large and complex data types

- gold Open Access which fosters wider collaboration and increased citations

- maximum visibility for your research: over $100 \mathrm{M}$ website views per year

At $\mathrm{BMC}$, research is always in progress.

Learn more biomedcentral.com/submissions 